\title{
An Abrasive Wear Model of Knife Milling to Predict the Impact of Material Properties and Milling Parameters on Knife Edge Recession
}

Applied Materials Division 


\begin{abstract}
About Argonne National Laboratory
Argonne is a U.S. Department of Energy laboratory managed by UChicago Argonne, LLC under contract DE-AC02-06CH11357. The Laboratory's main facility is outside Chicago, at 9700 South Cass Avenue, Lemont, Illinois 60439. For information about Argonne and its pioneering science and technology programs, see www.anl.gov.
\end{abstract}

\title{
DOCUMENT AVAILABILITY
}

Online Access: U.S. Department of Energy (DOE) reports produced after 1991 and a growing number of pre-1991 documents are available free at OSTI.GOV (http://www.osti.gov/),

a service of the US Dept. of Energy's Office of Scientific and Technical Information.

Reports not in digital format may be purchased by the public from the National Technical Information Service (NTIS):

U.S. Department of Commerce

National Technical Information Service

5301 Shawnee Road

Alexandria, VA 22312

www.ntis.gov

Phone: (800) 553-NTIS (6847) or (703) 605-6000

Fax: (703) 605-6900

Email: orders@ntis.gov

Reports not in digital format are available to DOE and DOE contractors from the Office of Scientific and Technical Information (OSTI):

U.S. Department of Energy

Office of Scientific and Technical Information

P.O. Box 62

Oak Ridge, TN 37831-0062

www.osti.gov

Phone: (865) 576-8401

Fax: (865) 576-5728

Email: reports@osti.gov

\section{Disclaimer}

This report was prepared as an account of work sponsored by an agency of the United States Government. Neither the United States Government nor any agency thereof, nor UChicago Argonne, LLC, nor any of their employees or officers, makes any warranty, express or implied, or assumes any legal liability or responsibility for the accuracy, completeness, or usefulness of any information, apparatus, product, or process disclosed, or represents that its use would not infringe privately owned rights. Reference herein to any specific commercial product, process, or service by trade name, trademark, manufacturer, or otherwise, does not necessarily constitute or imply its endorsement, recommendation, or favoring by the United States Government or any agency thereof. The views and opinions of document authors expressed herein do not necessarily state or reflect those of the United States Government or any agency thereof, Argonne National Laboratory, or UChicago Argonne, LLC. 


\section{An Abrasive Wear Model of Knife Milling to Predict the Impact of Material Properties and Milling Parameters on Knife Edge Recession}

by

George Fenske and Oyelayo Ajayi

Applied Materials Division, Argonne National Laboratory

August 2021 



\section{CONTENTS}

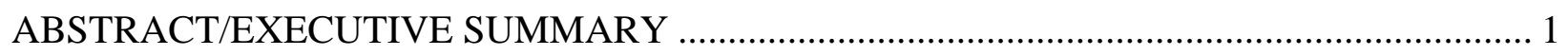

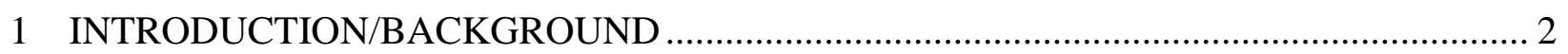

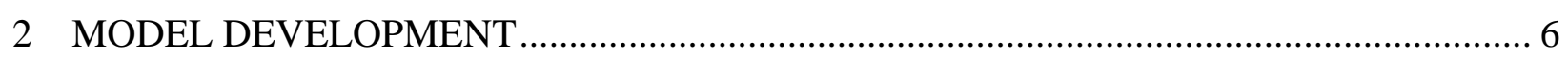

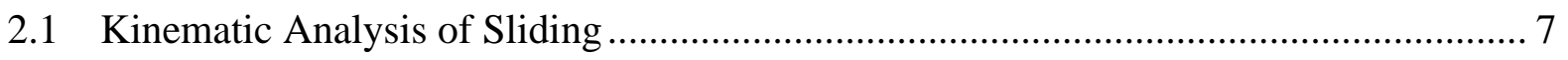

3 APPLICATION OF MODEL TO PREDICT CUTTER WEAR …………………………..... 11

3.1 Case 1: Impact of Particle Load............................................................................. 12

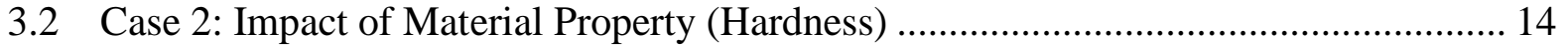

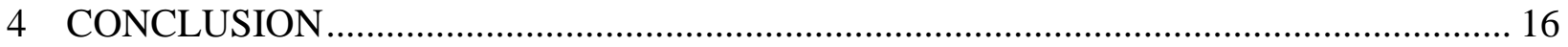

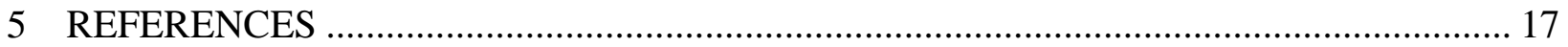

\section{FIGURES}

1 Major unit operations used in the comminution of biomass feedstocks................................. 2

2 Illustration of internal layout of knives inside a knife mill (cutting mill, granulator,

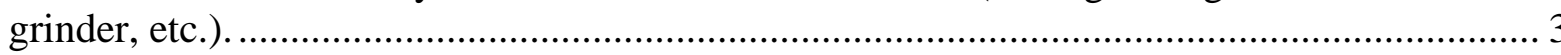

3 Optical images of new and worn knives illustrating edge recession (a) and abrasive wear tracks on rake (b) and flank (c) faces........................................................................ 3

4 Physical model of knife-milling operation: larger biomass chips are trapped between stationary and rotating knives and chips are cut, sheared, or torn into smaller pieces.

5 Illustration of hard inorganic ash particles trapped between chip and leading knife edge and embedding of particles into biomass and knife surface............................................ 5

6 Illustration of the volume of material worn as a particle of diameter D slides a distance $\mathrm{L}$ across the surface. "h" represents the indentation depth, and "d" represents the diameter of the indentation as measured on the original surface.

7 Illustration of stationary and rotating knives positioned in a knife mill. Gradual wear/recession of leading edges causes the flank face to assume a shape that mirrors

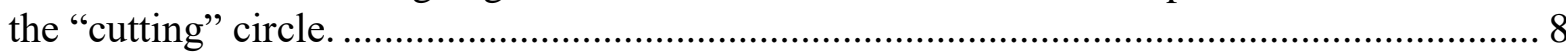

8 Conceptualization of the "arc of engagement" for a rotating knife........................................ 9

9 Schematic showing incremental volume of material worn from knife edge. …....................... 9

10 Predicted knife-edge recession as a function of particle load for 50 - to $600-\mu \mathrm{m}$ ash particles.

11 Predicted edge recession after $24 \mathrm{hr}$ operation at $1200 \mathrm{rpm}$ as function of particle load. 


\section{FIGURES (CONT.)}

12 Predicted edge recession of rotating knives after 24 hours of operation at $1200 \mathrm{rpm}$ for materials with different edge hardnesses.

\section{TABLES}

1 Material attributes and operating parameters used to model abrasive wear of

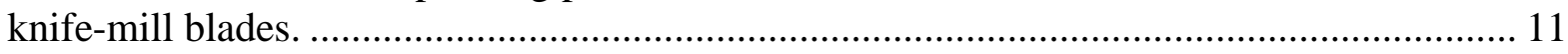

2 Calculated loads for different particle sizes .............................................................. 12 


\begin{abstract}
EXECUTIVE SUMMARY
A workable analytical abrasion model that relates critical knife-mill process parameters (geometry and rotational speed) to critical material attributes of inorganic mineral species in feedstock (density, size, and aspect ratio) and substrate (hardness and elastic modulus) was formulated to model wear of knives in knife-milling systems. Results of the model were compared to experimental observations of the edge recession of knives used in a knife mill marketed by Eberbach. Results showed good agreement between the predicted and measured shape of a worn knife and showed that a quality-by-design approach can be developed to predict component reliability based on scientific engineering principles in lieu of trial-and-error approaches.
\end{abstract}




\section{INTRODUCTION/BACKGROUND}

There is considerable interest worldwide in developing processes to transform nonfood sources of biomass into bioproducts, biofuels, and bioenergy. The U.S. Department of Energy's Bioenergy Technologies Office supports activities to develop innovative technologies for converting biomass into usable products, fuels, and energy, including activities on Feedstock Supply \& Logistics, Algal Biofuels, Sustainability, Analysis, and Conversion Technologies [1]. Recognizing the importance of pretreatment of biomass feedstocks for the development of valueadded products [2-4], the Feedstock Conversion Interface Consortium (FCIC;

https://fcic.inl.gov) develops first-principles-based knowledge and tools to understand the effects of biomass properties and process variability on pretreatment operations.

Pretreatment of biomass feedstocks is an essential step in changing the structure of lignocellulosic fractions into a state that responds to enzymatic hydrolysis. Pretreatment processes involve a number of unit operations requiring milling, grinding, cutting, and mechanical transport of feedstock from one stage to another. Because of the nature of mechanical interactions between feedstock (and ash) and surfaces of materials of construction, wear can occur and limit the reliability and functionality/performance of critical unit operations.

Preprocessing of biomass feedstocks entails a number of unit operations that involve mechanical operations that can result in wear of components [5]. These operations include bale processing (deconstruction/shredding of corn stover bound up into square/rectangular or round bales weighing approximately $1 / 2$ ton) and size-reduction operations to yield loose, free flowing biomass that can be readily treated by downstream pretreatment and conversion/digestion processes. Additional processing steps are often used to remove rock, gravel, sand and nonferrous metallic contaminants and to classify/separate the biomass by size and anatomical fractions prior to size reduction operations [6]. Figure 1 illustrates the flow diagram of major preprocessing operations used in the comminution of biomass feedstock. The operations shaded in blue represent those sensitive to mechanical wear phenomena that can degrade performance and productivity.

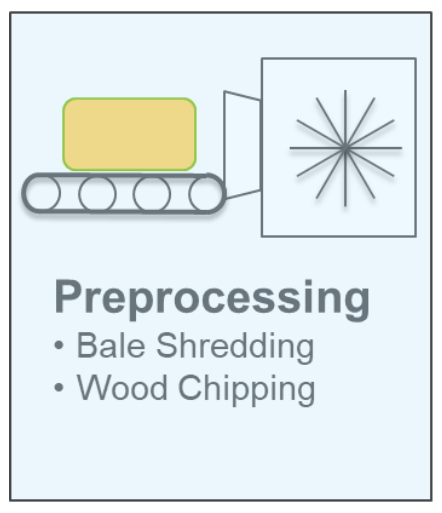

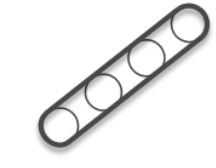

Separation \& Classification

- Contaminants

- Anatomical

fractionation
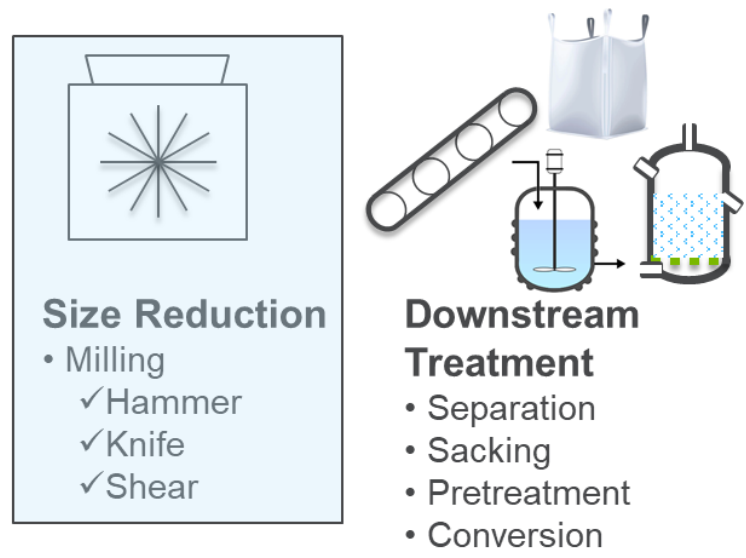

FIGURE 1 Major unit operations used in the comminution of biomass feedstocks (adapted from [7] with permission). 
One of the approaches under consideration for secondary size reduction of biomass (wood chips or corn stover) down to sizes required for downstream treatment is knife milling. Knife-milling steps are found in many size-reducing operations; Jordan Reduction Solutions [8] markets several lines of equipment used for comminution of biomass, plastics, metals, and municipal solid waste (MSW). Their products include shredders (rotary shears) as well as granulators and grinders (linear knife mills). Eberbach Corporation markets blending, mixing, and sizing equipment for pharmaceutical, food, beverage, and agricultural applications [9]. A schematic of a "bench-scale" knifemilling unit illustrating the internal layout of knives (stationary and rotating) is shown in Figure 2. The unit is approximately 8 " $(20 \mathrm{~cm})$ in diameter by $4 "(10 \mathrm{~cm})$ long. The central hub rotates at speeds up to $3000 \mathrm{rpm}$, producing rotational speeds ( $\mathrm{r} \omega)$ up to $32 \mathrm{~m} / \mathrm{s}$.

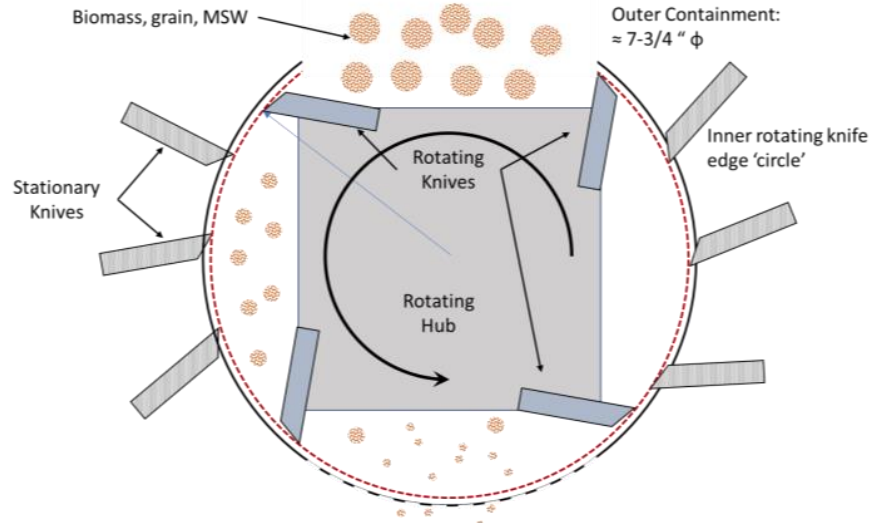

FIGURE 2 Illustration of internal layout of knives inside a knife mill (cutting mill, granulator, grinder, etc.). (Source: Argonne National Laboratory)

Figure 3 shows a series of optical micrographs of new and worn knife blades that illustrate the wear/recession of the leading edge. Figure 3a shows the cross section of a worn blade placed over the cross section of a new blade. The new blade is sharp and exhibits a "pointy" edge, while the worn edge is rounded and blunt - in this case, the leading edge has receded approximately 200 to $300 \mu \mathrm{m}$ from the original unworn location. If allowed to go far enough, the rounding/recession of the leading edge will be of such a magnitude that the mechanism by which the size reduction of the feedstock occurs will transition from a cutting mode, where sharp, well-defined particles are produced, to shearing or tearing modes that produce irregular, fragmented shapes [10]. Figures $3 b$ and $3 c$ show optical images of the rake (3b) and flank (3c) faces of the worn knife blade adjacent to the leading edge. Both faces show the presence of scratches caused by inorganic mineral particles (ash) sliding across the surfaces.
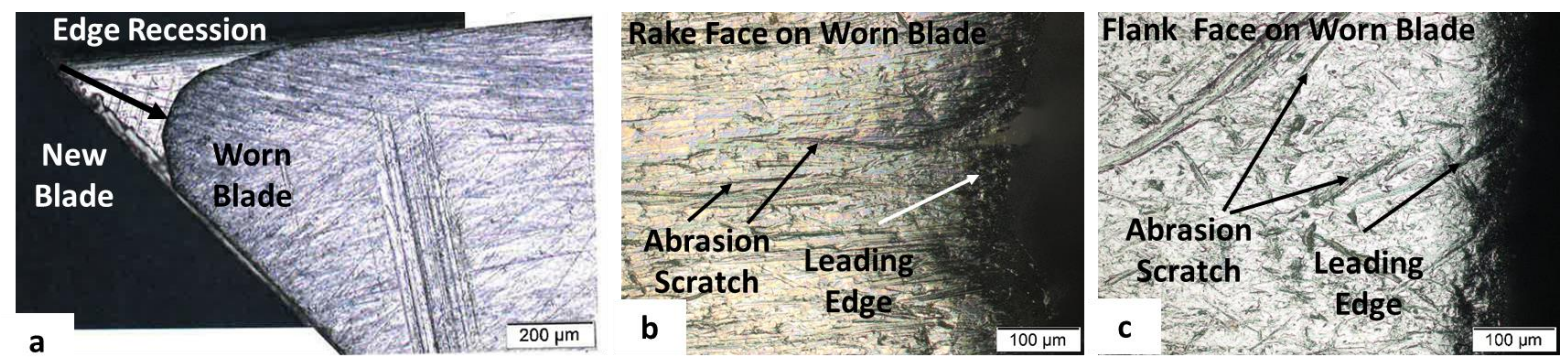

FIGURE 3 Optical images of new and worn knives illustrating edge recession (a) and abrasive wear tracks on rake (b) and flank (c) faces. (Source: Argonne National Laboratory) 
The goal of the research presented below was the development of an analytical tool to predict the impact of feedstock properties (ash content, ash size and shape, hardness), knife properties (hardness, elastic modulus), and process parameters (kinematics of motion, mill size, feed rate, residence time, etc.) on knife wear/edge recession. The results presented in this report describe efforts to develop and apply a mechanistic model of wear based on physical mechanisms involved in abrasion to predict wear of the leading edge-information that will enable plant designers and operators to understand how variabilities in feedstock properties and materials of construction can influence plant durability, reliability, and resilience to off-spec feedstock, and to better schedule preventative maintenance, or to identify suitable materials to extend lifetime.

Figure 4 shows a schematic of the interaction between the stationary and rotating knives that results in the cutting of biomass chips into smaller chips. Larger biomass chips, along with inorganic ash particles, enter the mill and are transported through the mill. As the rotating knives rotate past stationary knives, they trap biomass chips between them, and the chips are locally compressed as the gap between the leading edges decreases. If the stress at the leading edge exceeds the fracture stress of the biomass chip, one of several phenomena can occur [10], depending on the gap/clearance between the stationary and rotating knives: cutting if the gap is sufficiently small, shearing if the gap opens and spreads the force over the entire chip thickness, or

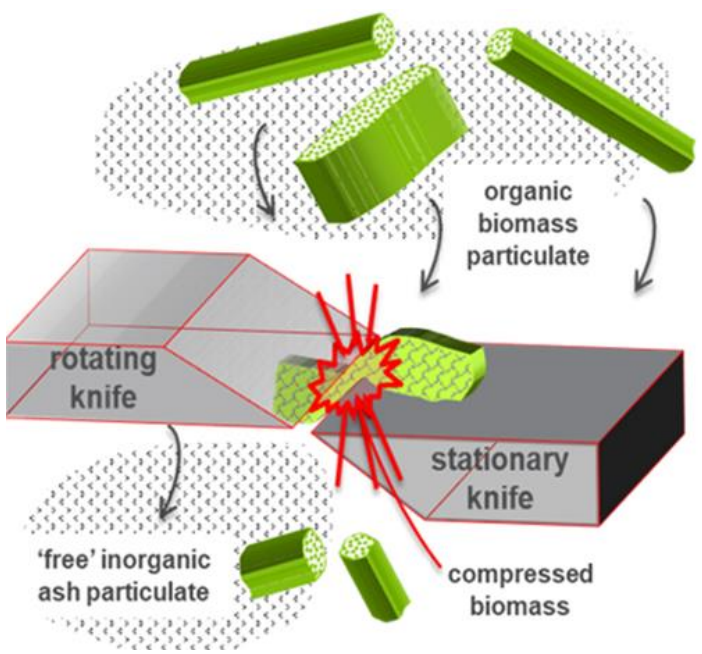

FIGURE 4 Physical model of knifemilling operation: larger biomass chips are trapped between stationary and rotating knives and chips are cut, sheared, or torn into smaller pieces. (Source: Argonne National Laboratory) tearing if the gap is sufficiently large.

Inorganic particles trapped between the biomass chip and the leading knife edge as the edges rotate past one another are embedded into the biomass and knife edge. The hard inorganic particles are primarily embedded into the biomass and partially into the knife edge, as illustrated in Figure 5. As the rotating knife slides/rotates past the stationary knives, the portion of the hard particle indenting the rotating knife abrades/scratches the leading edge. The process illustrated in Figure 5 is very similar to the chemical mechanical polishing (CMP) that is used industrially to finish components. The model developed below is based on approaches used to model the wear of silicon wafers polished by CMP [11,12]. This approach was recently applied to model abrasive wear [13] in a rotary shear concept developed by Forest Concepts [14]. 

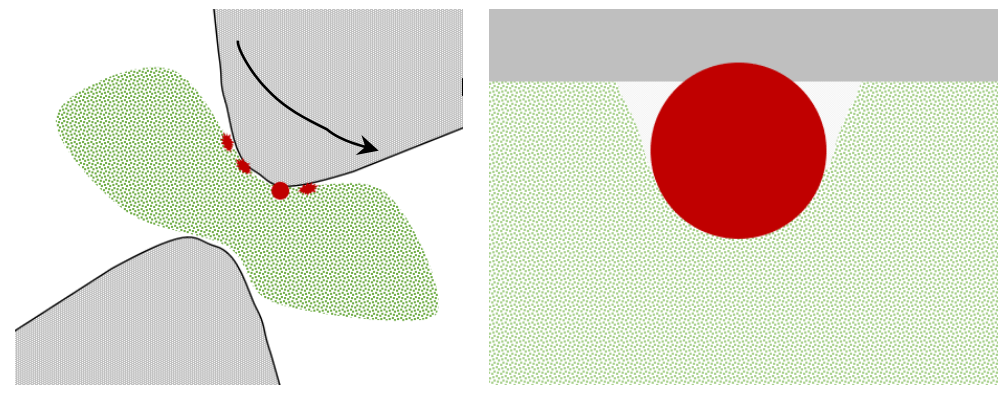

FIGURE 5 Illustration of hard inorganic ash particles trapped between chip and leading knife edge (left) and embedding of particles into biomass and knife surface (right). 


\section{MODEL DEVELOPMENT}

The rotary shear model began with the development of a constitutive equation for abrasive wear to calculate the volume of material lost, $\Delta \mathrm{V}$, as a particle slides across a surface. The model is illustrated in Figure 6 [13], which depicts a particle of diameter $\mathrm{D}$, subjected to a load, $\mathrm{W}$, that slides a distance $L$ across the surface. Because of the applied load, the particle elastically or plastically penetrates a distance " $h$ " into the surface. The amount of material worn is thus the volume of a semicircular trough, which, geometrically, is given as [15]

$$
\operatorname{Vol}\left(m^{3}\right)=\frac{\left[(D / 2)^{2}\right]}{2}(\alpha-\sin \alpha) x L
$$

where $\alpha$ is the central angle as shown in Figure 6, and $L$ is the sliding distance. The central angle, $\alpha$,

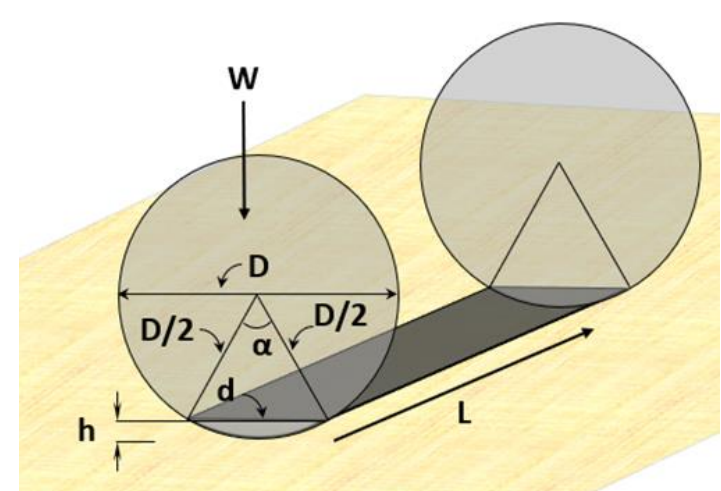

FIGURE 6 Illustration of the volume of material worn as a particle of diameter $D$ slides a distance $L$ across the surface. " $h$ " represents the indentation depth, and "d" represents the diameter of the indentation as measured on the original surface. can be obtained geometrically as

$$
(D / 2) \cos (\alpha / 2)=(D / 2)-h
$$

or

$$
\alpha=2 \operatorname{acos}[1-2 h / D]
$$

The indentation depth, h, depends on the nature of the deformation process. Under light loads (W), the deformation will be elastic in nature. At some critical load, plastic flow will begin to take place below the surface, resulting in elastoplastic behavior. At even higher loads, the deformation is fully plastic. A Hertzian treatment is used to model " $h$ " as a function of load, elastic modulus, and particle size for elastic interactions:

$$
W_{e}=\frac{4}{3} E^{*} \sqrt{D / 2} h^{3 / 2}
$$

where $\mathrm{E}^{*}$ is the composite/reduced elastic modulus of the particle and flat:

$$
E^{*}=1 /\left[\frac{1-v_{1}^{2}}{E_{1}}+\frac{1-v_{2}^{2}}{E_{2}}\right]
$$

where $v_{1}, v_{2}$, and $E_{1}, E_{2}$, are Poisson's ratio and elastic moduli, respectively, of materials (particle/biomass or particle/knife). 
A plastic deformation treatment is used for plastic interactions:

$$
W_{p}=H * \pi * D * h,
$$

where $\mathrm{H}$ is the hardness and $\mathrm{h}$ is the indentation depth.

We therefore have two solutions for the indentation depth, a pure elastic solution (eq. 4) or a fully plastic one (eq. 6). The decision as to which solution to use to calculate "h" depends on hardness, elastic modulus, and particle size and load. The approach used by Zhao et al. [11,12] for CMP was applied to estimate the critical indentation depth, $\mathrm{h}_{\mathrm{i}}$, where the deformation behavior transitions from pure elastic to elasto-plastic behavior, and the critical depth, h2, where the deformation is fully plastic. The equations for $h_{i}$ and $h_{2}$ are given as

$$
\begin{gathered}
h_{i}=\left[3 \pi k H / 4 E^{*}\right]^{2}(D / 2), \\
h_{2}>\left[3 \pi H / 2 E^{*}\right]^{2}(D / 2)>4 h_{i} / k^{2},
\end{gathered}
$$

where $\mathrm{k}$ is a mean contact pressure factor that correlates the mean contact pressure for initial yielding with the hardness. Using material properties typical of woody biomass, and typical materials used for construction of the cutters used for the rotary shear modeled in reference [13], it was determined that the interactions between the inorganic ash particles (representative of silica) and the biomass (pine), and between the particle and the cutter (steel), are plastic in nature and that eq. 6 can be used to determine "h" as a function of load, hardness, and particle size.

\subsection{Kinematic Analysis of Sliding}

According to the geometrical model of the material removed (eq. 1), the volume of material removed is proportional to the cross-sectional area of the semicircular cross-section and the sliding length $L$. The cross-sectional area can be calculated using eq. 6 coupled with eqs. $2 \&$ 3 , given the particle size, hardness, and applied load. Calculation of the sliding distance, $L$, requires analysis of the kinematic motion of the rotating knife past the stationary blades.

Figure 7 shows an end-on view of the layout of stationary and rotating knives in a knife mill. The stationary knives are aligned such that the cutting edges are positioned on a common "cutting" circle. The rotating knives are typically aligned such that the radial gap between the knife edges is approximately 100 to $200 \mu \mathrm{m}$, the thickness of a high-quality sheet of paper. As the leading edge wears/recesses, the flank face will recede and take on a shape that mirrors the radius of the stationary-knife cutting radius (slightly less than the stationary-knife circle), as illustrated in the middle and right-hand side of Figure 7. 

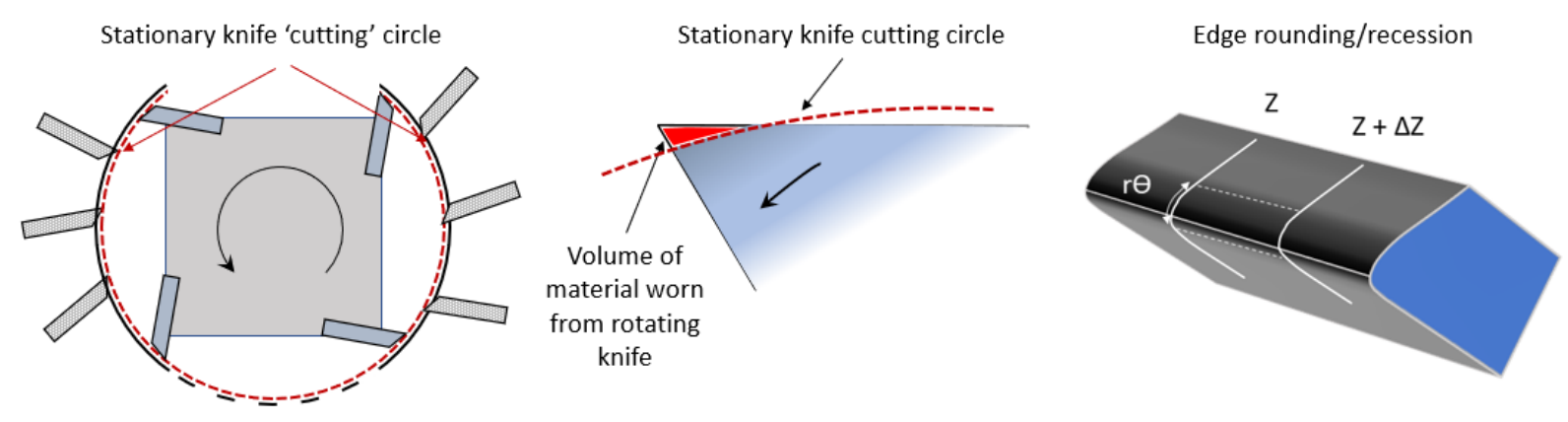

FIGURE 7 Illustration of stationary and rotating knives positioned in a knife mill. Gradual wear/recession of leading edges causes the flank face to assume a shape that mirrors the "cutting" circle.

Starting with the constitutive equations for abrasive wear (eqs. 1-6), the volumetric loss of material per revolution per stationary blade between $Z$ and $Z+\Delta Z$ as defined in the right-hand image in Figure 7 can be mathematically represented as

$$
\Delta V\left(\frac{m^{3}}{\text { particle }} / \text { revolution }\right)=\left(\frac{1}{2}\right)\left(\frac{D_{p}}{2}\right)^{2} *(\alpha-\sin \alpha) * S L * \# \text { particles between } Z \& Z+\Delta Z
$$

where $\mathrm{SL}=$ scratch length on knife edge, $\mathrm{SL} \approx \mathrm{r} \Theta$

$\mathrm{r}=$ distance from hub center to rotating-knife edge;

$\Theta=$ angle of inclusion of knife edge (Figure 7);

and $\quad$ particles between $\mathrm{Z}$ and $\mathrm{Z}+\Delta \mathrm{Z}$ is the number of particles on a line starting at $\mathrm{Z}$ and ending at $\mathrm{Z}+\Delta \mathrm{Z}$. Mathematically,

$\#$ particles $/ m=X * \Delta Z$,

where $\quad X=$ areal density of particles on surface $\left(\right.$ particles $\left./ \mathrm{m}^{2}\right)$ residing on knife edge.

Rewriting eq. 9, we obtain

$$
\Delta V=\left(\frac{1}{2}\right)\left(\frac{D_{p}}{2}\right)^{2} *(\alpha-\sin \alpha) * r \theta * X \Delta Z *(\operatorname{arc~of~engagement})
$$


where the arc of engagement is the average distance before each stationary knife at which a rotating-knife edge contacts/rubs against a biomass chip and undergoes abrasion. See Figure 8 for a graphical illustration of the arc length.

Mathematically, it can be shown that

$$
\operatorname{ArC}_{\text {engagement }}=\frac{\pi}{4} N_{\text {chip }} D_{\text {chip }}^{2}
$$

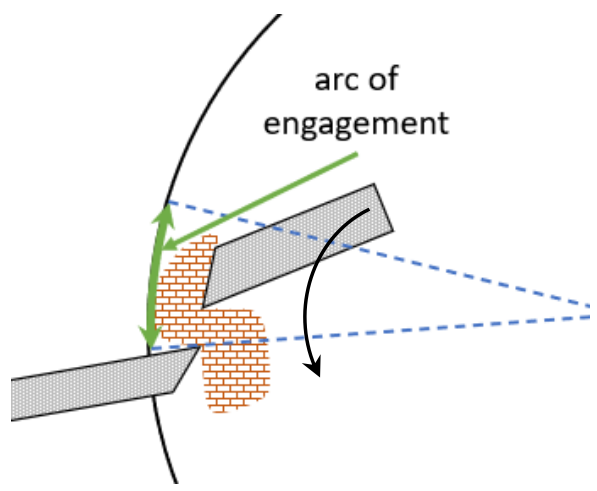

FIGURE 8 Conceptualization of the "arc of engagement" for a

Equation 10 then becomes rotating knife.

$$
\Delta V=\left(\frac{1}{2}\right)\left(\frac{D_{p}}{2}\right)^{2} *(\alpha-\sin \alpha) * r \theta * \chi \Delta Z * \frac{\pi}{4} N_{\text {chip }} D_{\text {chip }}^{2}
$$

The next step in the analysis is to equate the volume of material removed (eq. 11) to the incremental volume of material as shown in Figure 9. The incremental volume, $\Delta v$, is defined as

$$
\Delta v=\Delta_{\perp} * \mathrm{r} \Theta * \Delta \mathrm{Z},
$$

where $\Delta_{\perp}$ is the linear recession of the knife edge.

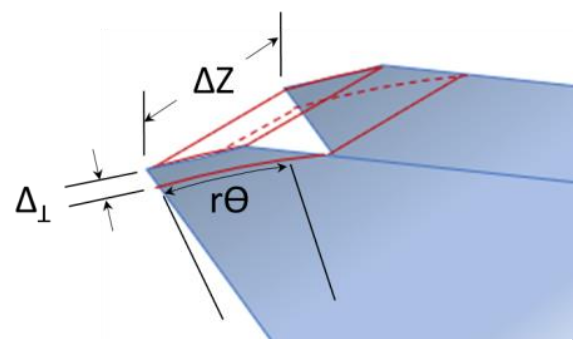

FIGURE 9 Schematic showing incremental volume (outlined in red) of material worn from knife By equating $\Delta \boldsymbol{v}$ (eq. 12) to $\Delta \mathrm{V}$ (eq. 11), we obtain edge.

$$
\Delta \perp * \mathrm{r} \theta * \Delta \mathrm{Z}=\left(\frac{1}{2}\right)\left(\frac{D_{p}}{2}\right)^{2} *(\alpha-\sin \alpha) * r \theta * \chi \Delta Z * \frac{\pi}{4} N_{\text {chip }} D_{\text {chip }}^{2}
$$

or

$$
\Delta_{\perp}=\left(\frac{1}{2}\right)\left(\frac{D_{p}}{2}\right)^{2} *(\alpha-\sin \alpha) * \mathcal{X} * \frac{\pi}{4} N_{\text {chip }} D_{\text {chip }}^{2} .
$$

The variable $\mathcal{X}$ (particles $/ \mathrm{m}^{2}$ ) is determined from several process parameters, including

- Biomass feed rate: $\mathrm{FR}(\mathrm{kg} / \mathrm{sec})$

- Ash content: AC (wt \%)

- Residence time: $\tau(\mathrm{sec})$ (dependent on rotational speed and included angle of the shear zone)

- Internal knife mill: $\quad \Delta \boldsymbol{v}\left(\mathrm{m}^{3}\right)$

- Particle size: D (m)

- Particle density: $\quad \rho_{\text {ash }}$ density of ash particles (e.g silica) $\left(\mathrm{kg} / \mathrm{m}^{3}\right)$

- Density of particles Particles $/ \mathrm{m}^{3}$ 
The linear chip density, $\mathrm{N}_{\text {chip }}$ (\# of biomass chips spaced along a stationary knife edge), is calculated in a similar manner to the ash particle density,

$$
\mathrm{N}_{\text {chip }}=\sqrt[3]{\text { chip density }}
$$

where the "chip density" (chips $/ \mathrm{m}^{3}$ ) depends on FR, residence time, internal mill volume, biomass chip density $\left(\mathrm{kg} / \mathrm{m}^{3}\right)$, and chip size/diameter (assumed to be $2 \mathrm{~cm}$ ). 


\section{APPLICATION OF MODEL TO PREDICT CUTTER WEAR}

Equation 14 was used to model the wear/recession of rotating knife-mill blades using the design of the Eberbach E3800 series cutting mills [9]. A series of Excel spreadsheets was developed to calculate wear/recession rates. The applications required information on several material attributes and operational parameters (listed in Table 1). Table 1 also includes a baseline case and the input parameters. The baseline case assumed the cutters were fabricated from AISI M2 tool steel and used properties obtained from a commercial material selection software package [14] and Eberbach knife suppliers.

TABLE 1 Material attributes and operating parameters used to model abrasive wear of knife-mill blades.

\begin{tabular}{|c|c|c|c|c|}
\hline \multicolumn{2}{|c|}{ Attribute/Parameter } & & & Baseline \\
\hline \multicolumn{5}{|c|}{ MILL DIMENSIONS } \\
\hline \multicolumn{2}{|c|}{ Mill Diameter (7-3/4") } & $M D$ & $\mathrm{~m}$ & $1.968 \mathrm{E}-01$ \\
\hline Mill Length (4") & & $M L$ & $\mathrm{~m}$ & $1.016 \mathrm{E}-01$ \\
\hline Hub Dimension & & Hub & $\mathrm{m}$ & $1.206 \mathrm{E}-01$ \\
\hline \multicolumn{2}{|c|}{ Inner Knife Diameter (7-1/4") } & IKD & $m$ & $1.841 \mathrm{E}-01$ \\
\hline Mill Speed (rpm) & & rpm & $\mathrm{rpm}$ & $1.200 E+03$ \\
\hline Rotational Speed & & $\omega$ & $\mathrm{rads} / \mathrm{sec}$ & $1.257 \mathrm{E}+02$ \\
\hline Rotations per day & & $N_{\text {day }}$ & & $1.728 \mathrm{E}+06$ \\
\hline \multicolumn{2}{|c|}{ Number of Rotating Blades } & NBrotating & & $4.000 \mathrm{E}+00$ \\
\hline \multicolumn{2}{|c|}{ Number of Stationary Blades } & $N B_{\text {stationary }}$ & & $6.000 \mathrm{E}+00$ \\
\hline Internal Volume & & $V_{\text {internal }}$ & $\mathrm{m}^{3}$ & $1.613 \mathrm{E}-03$ \\
\hline \multicolumn{2}{|c|}{ Residence Time $(0.1-10 \mathrm{sec})$} & $\tau$ & $\mathrm{sec}$ & $1.000 \mathrm{E}-01$ \\
\hline Transit Time & & & & $2.500 \mathrm{E}-02$ \\
\hline \multicolumn{5}{|c|}{ FEEDSTOCK ATTRIBUTES } \\
\hline Feed Rate & & $F R$ & $\mathrm{~kg} / \mathrm{sec}$ & $5.000 \mathrm{E}-02$ \\
\hline \multicolumn{2}{|c|}{ Ash Content $(1,10$ wt\%) } & $A C$ & wt \% & $1.000 \mathrm{E}+00$ \\
\hline Biomass Density & & $\rho_{\text {biomass }}$ & $\mathrm{kg} / \mathrm{m}^{3}$ & $6.000 \mathrm{E}+02$ \\
\hline \multicolumn{2}{|c|}{ Biomass Chip Size $(\mathrm{m})$} & $D_{\text {chip }}$ & $\mathrm{m}$ & $2.000 \mathrm{E}-02$ \\
\hline \multicolumn{2}{|c|}{ Biomass Hardness (Pa) } & $\mathrm{H}$ & $\mathrm{Pa}$ & $3.923 \mathrm{E}+07$ \\
\hline \multicolumn{2}{|c|}{ Biomass Elastic Modulus (Pa) } & $E$ & $\mathrm{~Pa}$ & $1.500 \mathrm{E}+09$ \\
\hline \multicolumn{2}{|c|}{ Biomass Poisson Ratio } & $\mathrm{v}$ & None & $3.000 \mathrm{E}-02$ \\
\hline \multicolumn{5}{|c|}{ ASH ATTRIBUTES } \\
\hline \multicolumn{5}{|c|}{ Identity (Silica/SiO2) } \\
\hline Ash Hardness (Pa) & & $\mathrm{H}$ & $\mathrm{Pa}$ & $9.800 \mathrm{E}+09$ \\
\hline \multicolumn{2}{|c|}{ Ash Elastic Modulus (Pa) } & $E$ & $\mathrm{~Pa}$ & $7.300 E+10$ \\
\hline Ash Poisson Ratio & & $\mathrm{v}$ & none & $1.500 \mathrm{E}-01$ \\
\hline Particle Diameter & & $D_{p}$ & $\mathrm{~m}$ & $1.00 \mathrm{E}-04$ \\
\hline \multicolumn{2}{|c|}{ Particle Shape Factor } & $\eta$ & none & 1 \\
\hline Wear Constant & & $K$ & none & 1 \\
\hline Particle Density & & $\rho_{\text {ash }}$ & $\mathrm{kg} / \mathrm{m}^{3}$ & 2600 \\
\hline
\end{tabular}


TABLE 1 (Cont.)

\begin{tabular}{|c|c|c|c|}
\hline Attribute/Parameter & & & Baseline \\
\hline \multicolumn{4}{|c|}{ KNIFE ATTRIBUTES } \\
\hline Material of Construction & & & M2 \\
\hline Hardness (Pa) & $\mathrm{H}$ & $\mathrm{Pa}$ & $7.35 \mathrm{E}+09$ \\
\hline Elastic Modulus (Pa) & E & $\mathrm{Pa}$ & $2.25 \mathrm{E}+11$ \\
\hline Poisson Ratio & v & none & 0.29 \\
\hline
\end{tabular}

Examples of the application of the model and the sensitivity to the input parameters are presented below. The calculations were all run assuming the particles were of uniform size, i.e., no distribution of sizes.

1. The first set of comparisons demonstrates the impact of particle load, W, on the predicted wear/recession of the knife edge. Calculations were performed with the following assumptions: $1 \%$ ash content, with particle sizes ranging from $50 \mu \mathrm{m}$ to $600 \mu \mathrm{m}$. For the intial runs, the shape factor was set to 1 , as was the wear constant. Calculations of the nominal load experienced by each particle are presented in Table 2:

TABLE 2 Calculated loads for different particle sizes

\begin{tabular}{|c|c|c|c|c|c|c|c|}
\hline$D_{p}(\mu \mathrm{m})$ & 50 & 100 & 200 & 300 & 400 & 500 & 600 \\
\hline Load (N) & 0.077 & 0.308 & 1.232 & 2.773 & 4.930 & 7.702 & 11.091 \\
\hline
\end{tabular}

2. The second example will demonstrate the impact of hardness on the wear behavior. Results are presented for knives with edge hardness ranging from $500 \mathrm{H}_{\mathrm{v}}$ to $1500 \mathrm{H}_{\mathrm{v}}$.

\subsection{Case 1: Impact of Particle Load}

In this study, the impact of the load applied to the ash particles is examined. Results of the simulation (for $1 \%$ ash, shape factor $\eta=2$, wear constant $K=0.1$, residence time $\tau=0.1 \mathrm{sec}$, and hardness $\mathrm{H}_{\mathrm{v}}=735$ ) are shown in Figure 10 for ash particle diameters ranging from $50 \mu \mathrm{m}$ to $600 \mu \mathrm{m}$. 


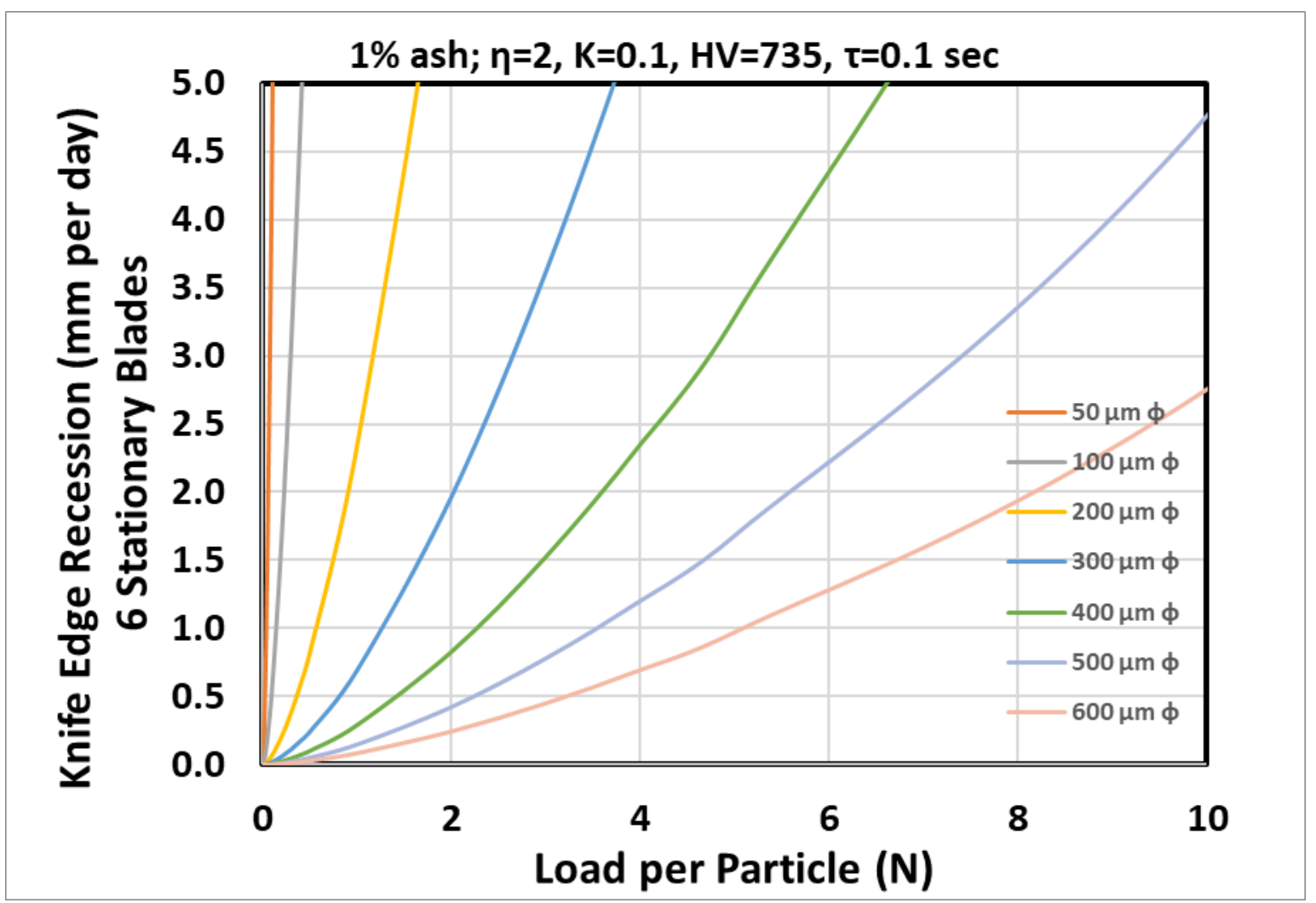

FIGURE 10 Predicted knife-edge recession (eq. 14) as a function of particle load for 50- to 600- $\mu \mathrm{m}$ ash particles.

Figure 10 suggests that smaller particles cause much more wear/recession than larger particles; this observation, however, is misleading when one considers the force imposed on a particle as it is embedded into the biomass chip. Larger particles will require a larger force, and if we assume that the load imposed on a particle is proportional to the size of the particle and the hardness of the biomass, one can estimate the load carried by each particle to be

$$
W_{p}=H_{\text {chip }} * \pi *\left(\frac{D_{p}}{2}\right)^{2}
$$

By overlaying the predicted particle loads for different particle diameters from eq. 15 on the curves in Figure 10, it is possible to locate the recession for a given particle size as shown in Figure 11, where the red stars represent the recession for the calculated loads, $\mathrm{W}_{\mathrm{p}}$. 


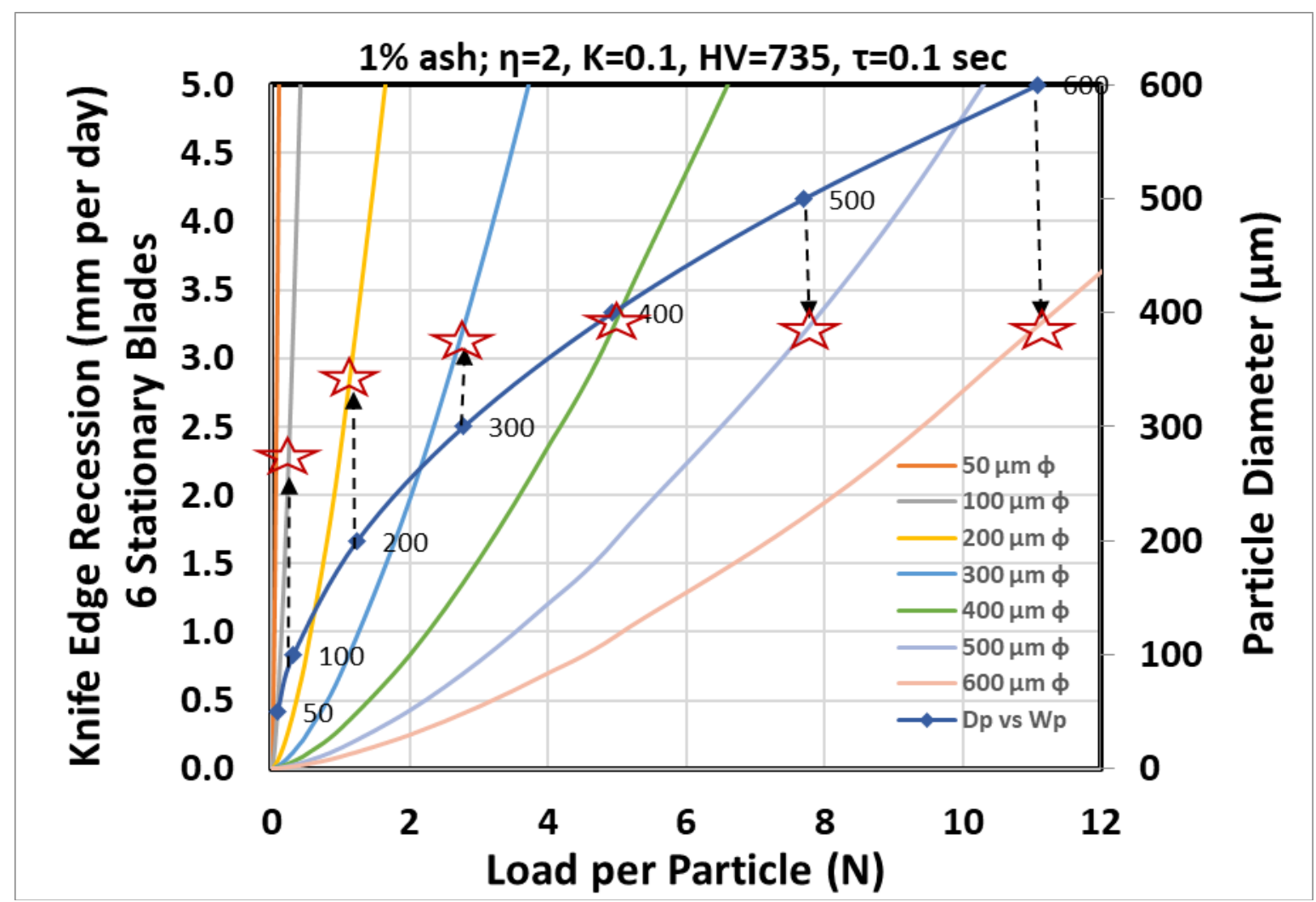

FIGURE 11 Predicted edge recession after $24 \mathrm{hr}$ operation at $1200 \mathrm{rpm}$ as function of particle load. The red stars represent locations of predicted particle loads from eq. 15 .

\subsection{Case 2: Impact of Material Property (Hardness)}

The second case study examines the impact of materials on wear/recession of the rotating-knife edge. The baseline case is knives fabricated from M2 tool steel typical of those provided on the Eberbach mill. The M2 knives are provided in a hardened/tempered state with a core Vickers hardness of $735 \mathrm{H}_{\mathrm{v}}$. Three additional cases were also -examined-one typical of a low-cost carbon steel (AISI 1095) heat treated and tempered to a core hardness of Rc 50 $\left(\approx 500 \mathrm{H}_{\mathrm{v}}\right.$ ); a second typical of a tool steel (core hardness Rc 60 ) covered with a hard coating, where the coating has a hardness of approximately $1000 \mathrm{H}_{\mathrm{v}}$; and a third typical of an alternative steel alloy treated with a chemical conversion process that produces thick borided layers with hardnesses of $1500 \mathrm{H}_{\mathrm{v}}$.

Results are shown in Figure 12, which shows predicted edge recession for hardnesses of $500 \mathrm{H}_{\mathrm{v}}$ (AISI 1095), $750 \mathrm{H}_{\mathrm{v}}\left(\mathrm{M} 2\right.$ tool steel), $1000 \mathrm{H}_{\mathrm{v}}$ (coated tool steel), and $1500 \mathrm{H}_{\mathrm{v}}$ (borided steel). The results are as expected; the harder materials ae not predicted to wear/recede as much as softer material, assuming hardness is the only factor affecting wear. Surface fatigue and toughness will also have an impact, but at the present time, only the effect of hardness was considered. 


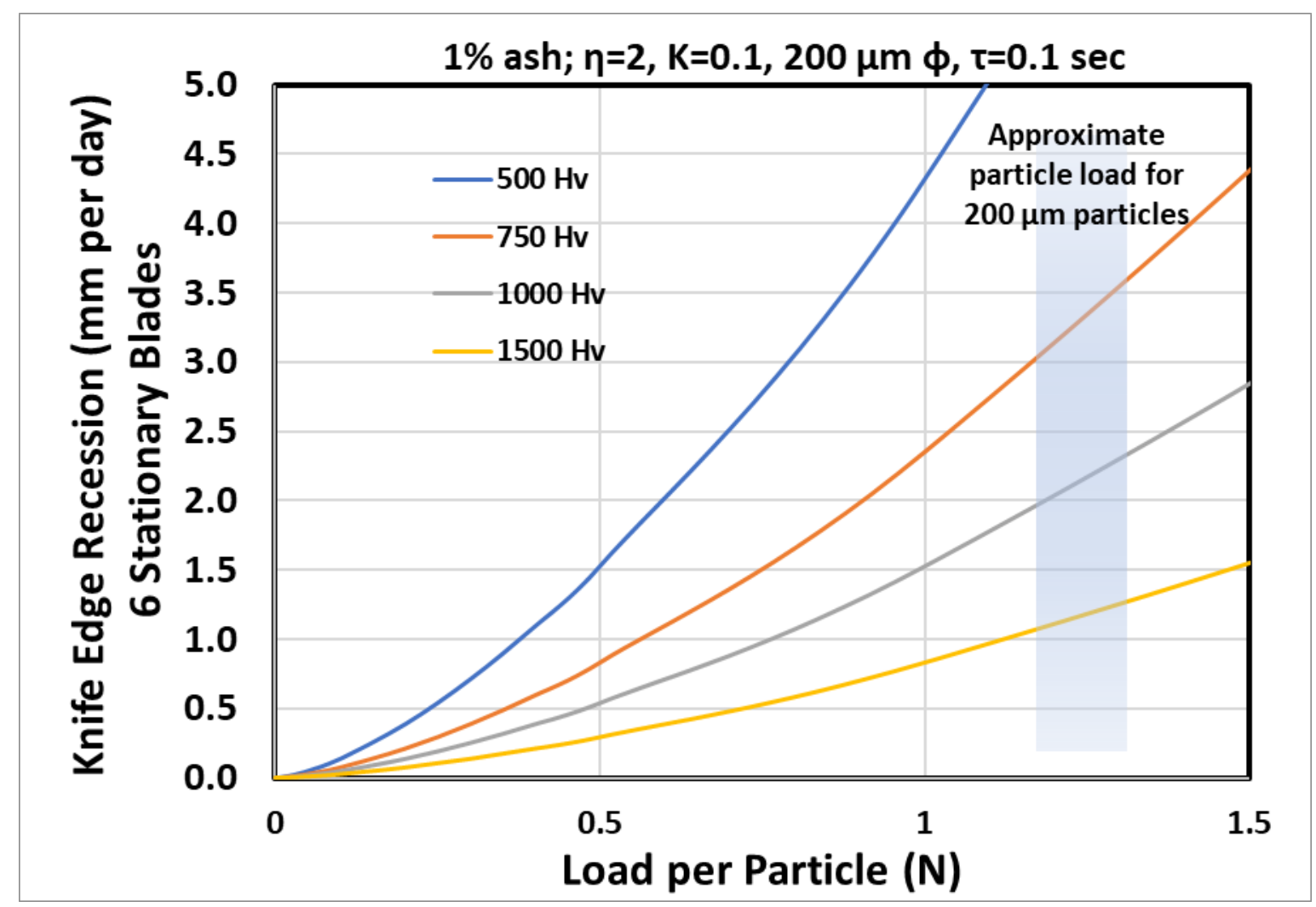

FIGURE 12 Predicted edge recession of rotating knives after 24 hours of operation at $1200 \mathrm{rpm}$ for materials with different edge hardnesses. 


\section{CONCLUSION}

An analytical model was developed from first principles and implemented to predict abrasive wear of the flank face of rotating knives in a high-speed knife mill. Several case studies were presented to evaluate the ability of the model to assess the impact of feedstock variability (ash size, ash content, ash shape, and moisture content through moisture-hardness correlations), process parameters (speed), and material attributes (knife hardness).

Along with applying due diligence, the analytical model can serve as the basis for developing a quality-by-design approach to guide optimization of knife-mill geometries (size and knife shape), operating conditions, and construction materials and to schedule maintenance outages based on operating history.

- Integration of model with FEM calculations of applied particle loads.

- Validation of the abrasive model against bench-scale and field tests, including but not limited to tracking of wear as a function of material/ash processed.

- Integration of the abrasion wear model on flank faces with an erosion wear model to predict wear on rake faces. 


\section{REFERENCES}

[1] Office of Energy Efficiency \& Renewable Energy, 2020, "Bioenergy Technologies." Available at https://www.energy.gov/eere/bioenergy.

[2] Julie Baruah, Bikash Kar Nath, Ritika Sharma, Sachin Kumar, Ramesh Chandra Deka, Deben Chandra Baruah, and Eeshan Kalita, 2018, "Recent Trends in the Pretreatment of Lignocellulosic Biomass for Value-Added Products," Frontiers in Energy Research 6, article 141. Available at www.frontiersin.org.

[3] Adepu Kiran Kumar and Shaishav Sharma, 2017, "Recent Updates on Different Methods of Pretreatment of Lignocellulosic Feedstocks: A Review," Bioresources and Bioprocessing 4, article 7. DOI 10.1186/s40643-017-0137-9.

[4] Solange Mussatto, ed., 2016, Biomass Fractionation Technologies for a Lignocellulosic Feedstock Based Biorefinery, Elsevier. ISBN: 978-0-12-802323-5.

[5] Edward Wolfrum, N.D., Feedstock Conversion Interface Consortium - Annual Review of Research - FY2020, report to DOE/EERE/BETO - in-preparation.

[6] Kyungjun Lee, Sougata Roy, Ercan Cakmak, Jeffrey A. Lacey, Thomas R. Watkins, Harry M. Meyer, Vicki S. Thompson, James R. Keiser, and Jun Qu, 2020, "CompositionPreserving Extraction and Characterization of Biomass Extrinsic and Intrinsic Inorganic Compounds," ACS Sustainable Chemical Engineering 8, 1599-1610.

[7] George Fenske and Oyelayo Ajayi, 2020, Identification of Critical Process Parameters for Knife Milling and Alternative Comminution Strategies, Argonne National Laboratory report ANL/AMD-20/3 (released for distribution through OSTI.gov).

[8] Jordan Reduction Solutions, https://www.jordanreductionsolutions.com/.

[9] Product Catalog, Eberbach Corporation, https://eberbachlabtools.com/pages/productcatalog.

[10] Petre I. Miu, E. J. Chapman, Alvin R. Womac, Igathinathane Cannayen, and Shahab Sokhansanj, 2006, "Analysis of Biomass Comminution and Separation Processes in Rotary Equipment-A Review," presented at the 2006 ASABE Annual International Meeting, Portland, OR, July 9-12, DOI: 10.13031/2013.21523.

[11] Y. Zhao, D. Marietta, and L. Chang, 2000, "An Asperity Microcontact Model Incorporating the Transition from Elastic Deformation to Fully Plastic Flow," Journal of Tribology 122(1), 86-93.

[12] Y. Zhao and L. Chang, 2002, "A Micro-Contact and Wear Model for Chemical-Mechanical Polishing of Silicon Wafers," Wear 252, 220-226. 
[13] George Fenske and Oyelayo Ajayi, 2021, "Develop a wear prediction model for the rotary shear comminution system based on fundamental understanding of the wear process and mechanisms," FCIC Milestone report for FY21, Q3, June.

[14] https://forestconcepts.com/forest-concepts-awarded-doe-funding-to-model-biomassbehaviors-and-downstream-conversion-effects/

[15] https://mathworld.wolfram.com/CircularSegment.html 



\section{Argonne 4}

\section{Applied Materials Division}

Argonne National Laboratory

9700 South Cass Avenue, Bldg. 362

Lemont, IL 60439-4832

www.anl.gov 